D. J. Blackwood, D. J. Gilmour, J. P. Isaacs, T. Kurka and R. E. Falconer

School of Science, Engineering and Technology, Abertay University, Bell Street,

Dundee, DD1 1HG

d.blackwood@abertay.ac.uk,

d.gilmour@abertay.ac.uk,

j.isaacs@abertay.ac.uk

t.kurka@abertay.ac.uk

r.falconer@abertay.ac.uk

WORD COUNT: 7,983 excluding references and list of authors.

This is the accepted manuscript of an article published by Sage in Environment and Planning B: Planning and Design on 26 September 2014. Published article is available from: doi: http://dx.doi.org/10.1068/b39080 


\section{SUSTAINABLE URBAN DEVELOPMENT IN PRACTICE: THE SAVE}

\section{CONCEPT}

\section{Abstract}

The need for sustainable development of the urban environment presents the research community with a number of challenges and opportunities. A considerable volume of research has been undertaken into the constituent parts of this complex problem and a number of tool kits and methodologies have been developed to enable and encourage the application of specific aspects of research in practice. However, there is limited evidence of the holistic integration of the body of knowledge arising from the research within real life decision making practices. This paper presents an overview of the existing body of knowledge relating to sustainable development of the urban environment and proposes a generic framework for its integration within current practices. This framework recognises the need to: understand social, economic and environmental issues; understand the decision-making processes; provide a means of measurement, assessment or valuation of the issues; to provide analytical methods for the comparative assessment of complex data to enable an evaluation of strategies and design options and to communicate effectively throughout the process with a wide range of stakeholders. The components of a novel Sustainability Assessment, Visualisation and Enhancement Framework (SAVE), developed by the authors to "operationalise" the body of knowledge are presented and justified. These include: decision mapping methods to identify points of intervention; indicator identification and measurement approaches; appropriate mathematical and analytical tools and an interactive simulation and visualisation platform which integrates and communicates complex multivariate information to diverse stakeholder groups. The paper reports on 
the application of the SAVE framework to a major urban development project and reflects on its current and potential impact on the development. Conclusions are also drawn in its general applicability.

Keywords: sustainability, decision analysis, visualisation.

\section{INTRODUCTION}

A considerable volume of research has been undertaken into sustainable development of the urban environment and a number of tool kits and methodologies have been developed to enable and encourage the application of specific aspects of research in practice (Walton et al, 2005). However, there is limited evidence of the holistic integration of the body of knowledge arising from the research within real life decision making practices.

This paper presents, justifies and reports on the application on an integrated framework for incorporating the concepts of sustainable development within the decision making processes for major urban development projects. The framework is justified through a review of sustainable development concepts and the associated practical barriers for their implementation. The components of the framework are then described, illustrated and assessed though the application of the framework to a case study project.

\section{SUSTAINABLE URBAN DEVELOPMENT: CONCEPTS AND CHALLENGES}

\subsection{Complexity and Timescale}

Sustainable urban development requires the effective engagement of a wide range of stakeholders such as planners, landscape architects, engineers, policy makers and the members of wider communities. These stakeholders will contribute to different stages 
of the development process and require information and data in a diverse range of forms to ensure that they are adequately informed and therefore able to make an effective contribution. Furthermore, major urban development projects extend over prolonged timescales e.g. up to 25 years in the case of major regeneration projects. Hunt et al (2005) identify five major stages in the development of such projects; Visioning, Feasibility, Design, Construction and Occupancy, noting that many of the key decisions that relate to sustainability are made early in the process during the Visioning and Feasibility stages.

Another complicating feature of the sustainability decision making process is the diverse nature of the information that is required to support a decision. Sustainable development is a vision of progress, which integrates immediate and longer term needs, local and global needs, and regards society, environment and economics as inseparable and interdependent. Therefore, if any development can be described as sustainable, it must integrate on a temporal basis economic, social and environmental issues.

\subsection{Rationality of the Decision Making Process}

The extent to which sustainability issues can be incorporated in projects is influenced by the degree of rationality of the decision making process. Rational decisions are desirable and could lead to optimal choices being made but require a highly specified and clearly defined environment. Most publications on decision making make reference to early work by Simon (1976), March and Simon (1958) and Lindblom (1959), who all noted that decision making in practice is seldom structured and that often "satisfactory" solutions are reached on an ad hoc basis. March and Simon 
question the ability of the "rational" decision maker to make optimal choices and distinguish between optimal and satisfactory solutions to problems. They conclude that most human decision making is concerned with the discovery and selection of satisfactory rather than optimal alternatives and describe this process as "satisficing".

The degree of rationality of the decision making process is also influenced by Asimow's (1962) concept of the "bases for decision" within the design process. This "bases for decision" must be related to evidence, and the "economic worth" of that evidence must be considered. That is the cost of obtaining evidence against the value of the evidence to the correctness of the decision. In essence, the quality of the solution may vary dependent upon the time and effort expended to produce a solution and although many "satisfactory" solutions may exist some, when guided by more complete evidence, are likely to be closer to the optimal solution than others.

\subsection{Incorporation of Sustainable Development Concepts in Practice}

Although a large body of work has been undertaken to conceptualise sustainable development and there is a wide awareness of it, it is generally accepted that the real challenge lies in understanding how to put it into practice, i.e. to "operationalise" sustainability.

This "operationalisation" of the principles of sustainable development within the urban design and development process must be fostered at a number of levels and requires a number of approaches. Beck et al (2011), explore the impact of forms of governance on the capacity for re-engineering to meet urban water needs of the future. Boyko, Cooper and Davey (2005) propose that urban design must be fostered at a more local level, involving not only local authorities, but the communities and local 
businesses. They note that a traditional planning approach views planning as a passive exercise with planners as rational decision makers using mainly quantitative approaches to data collection and analysis. They suggest a need for a higher conceptual decision making process involving elements of qualitative rational decision making but with the incorporation of more subjective information to maximise input from a wide range of stakeholders into the different stages of the planning process. Similarly Bell, Chivers and Hillier (2011) highlight the need for sufficient emphasis to be given to social factors in engineering design processes for urban infrastructure by the reframing of engineering practice from a focus on Ecological Modernisation to one of Socio-technical Engineering.

At a more practical level, a large number of tools, techniques and guidance documents have been produced to support decision makers in sustainable development decision making in the context of the urban environment. Bartlett and Guthrie (2005) undertook a comparative analysis of seventeen leading documents and concluded that sustainable development could be seen as "a process of ongoing development and maintenance of the built environment and secondly as a process toward intergenerational and intragenerational equity". This requires sustainability assessment, which has been defined as being concerned with the provision of "tangible information on key aspects of built environment sustainability, providing guidance during the decision-making process in a manner that is inclusive of the stakeholders involved" (Thomson, El-Harem and Emmanuel, 2011).

Assessment of progress towards sustainability is evaluated using indicators. There are many examples of sustainability indicator sets that have been developed in the last 
decade for a wide range of sectors, e.g. for the water industry (Water UK, 2000) and for bio-energy systems (Buchholz et al, 2009). CIRIA (2001) developed a suite of sustainable construction indicators and these were piloted by 10 companies in a later, CIRIA managed, project on their implementation (CIRIA, 2004). Whilst the CIRIA project found that the suite provided a suitable source of indicators for supporting the achievement of organisational targets, it demonstrated that no standard set of indicators was likely to be adopted by the industry as a whole. This confirmed previous research in the use of sustainability indicators by the authors (Ashley et al, 2008) and by others (e.g. Starkl \& Brunner, 2004) which recommended that indicators should be selected on a case by case basis.

Walton et al (2005) examined the extent to which current sustainability methodologies meet the need for integration. They identified a number of shortcomings including the need for:

An integrated multi-dimensional tool that could bring existing approaches together. Transparency and communication in the promotion of sustainability assessment amongst a wide ranging group of stakeholders.

Recognition of the context specific nature of sustainability analysis.

Inclusion of stakeholders in the assessment process.

\subsection{The SAVE Concept}

The review above has highlighted the concepts and challenges of sustainable urban development. It has demonstrated a need to develop a practical, integrated approach that can deal with the complexity and timescales of major projects whilst providing information in the right form and at the right time to a range of stakeholders to 
support more rational decision making. In response to these challenges, a Sustainability Assessment, Visualisation and Enhancement (SAVE) framework has been developed by the University of Abertay Dundee. The Framework is designed address the shortcomings of existing Sustainability Assessment methodologies and to support inclusive decision-making throughout all the stages of urban development projects. It includes:

A process for the selection of appropriate sustainability indicators that allow the assessment and monitoring of sustainability.

Modelling techniques that can provide data for the measurement of indicators and for the prediction of future trends.

Techniques to facilitate the effective communication of predicted current and future trends in sustainability to a wide range of stakeholders to enhance their engagement throughout the process thus enhancing public acceptance and participation and enhancing the rationality of the process

It is essential that the sustainability of a development is not only assessed and monitored as it progresses, but that actions and interventions are implemented at key points throughout the development process to steer the project towards the most desirable outcome. These actions and interventions can be termed Sustainability Enhancement activities.

\section{SAVE FRAMEWORK}

The SAVE framework promotes an integrated approach to inclusive decision making for sustainable development, involving three inter-related components; Assessment, Visualisation and Enhancement as shown in Figure 1. The Assessment and 
Enhancement components should commence together at the visioning stages of projects.

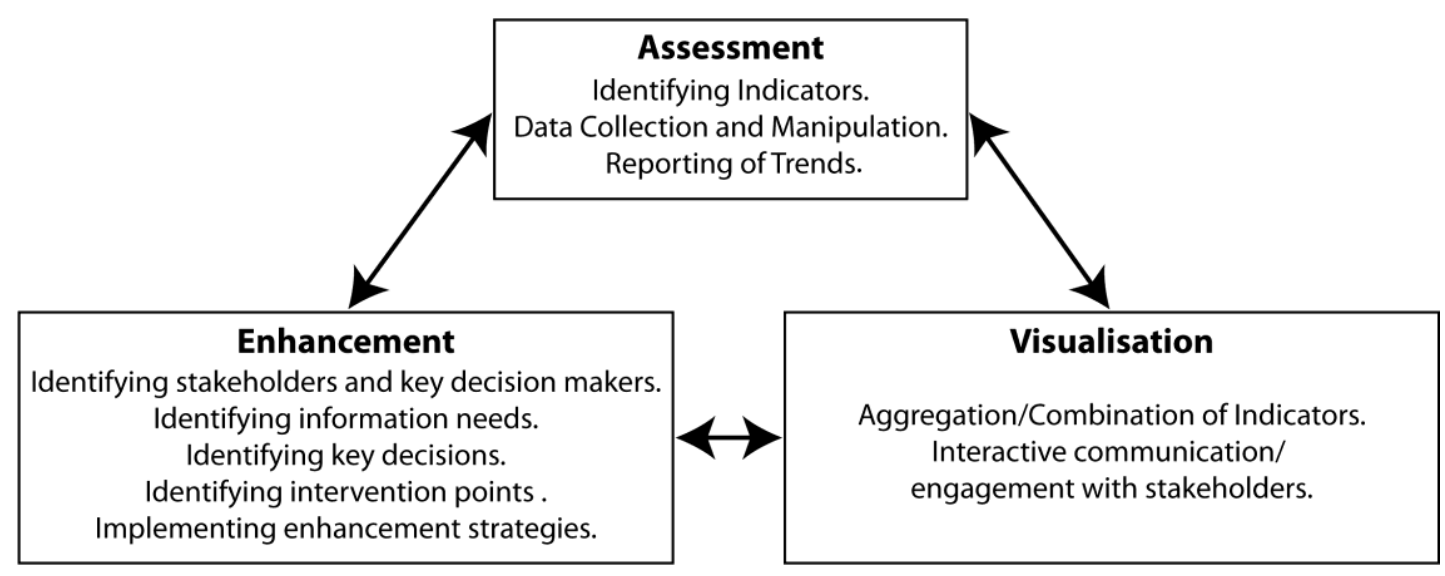

Figure 1. The SAVE Framework

The SAVE Assessment component provides the data that are necessary for sustainability assessment and monitoring throughout the life of a project. A sustainability benchmark should be established at the visioning stage of the development and continuously monitored through the design, construction and occupancy stages. The initial outcome from the assessment component is the Sustainability Indicator set and the initial measured or modelled values of these indicators define the pre-development baseline of sustainability. These are published in the Baseline Sustainability Assessment Report and the subsequent Sustainability Monitoring Report is published annually, which provides an update of the indicator values, enables assessment and reporting of changes and trends in sustainability to be identified and hence informs the SAVE Enhancement component.

The SAVE Enhancement component ensures that due consideration is given at key decisions points to the potential impact of decisions and actions on the direction of the Sustainability Assessment Indicators. The Enhancement component identifies opportunities to positively influence the sustainability of the development and enables 
the identification and implementation of appropriate activities and actions. The Enhancement component provides an understanding of the ways in which decisions are made throughout the project and enables the information needs of key decision makers to be determined. This ensures that information can be provided on the potential impact of decisions or actions that will influence the overall sustainability of the project to the right stakeholders, at the right time and in the right form. The final component of SAVE framework, the Visualisation component addresses the need for communication with a wide range of stakeholders. Stakeholder engagement is an essential element of enhancement activities, particularly in the early stages of a development where the decision process is in the ill-structured domain. The planning, design and construction of more sustainable infrastructure does not itself ensure sustainable behaviour by end-users. Sustainable urban development must facilitate the transition from current lifestyles to those required for a more sustainable long term future and this requires the early engagement of end users to ensure that the development is acceptable to them and will lead to more sustainable lifestyles. A simulation and visualisation tool (S-City VT) has been developed by the research team to enable all stakeholders, regardless of background or experience, to understand, interact with and influence decisions made on the sustainability of urban design. S-City VT takes the unique approach of combining 3D interactive and immersive technologies with computer simulation to present stakeholders with an interactive virtual development. The visualisation component facilitates effective stakeholder engagement in two ways. Firstly the use of novel immersive communication technologies helps convey the complex facets of sustainability to nonexpert stakeholders. Secondly, underlying temporal models of the sustainability indicator values can predict changes to indicators through time for a range of 
scenarios to allow stakeholders to understand the impacts of decisions and actions on future sustainability. This is particularly useful during the visioning, feasibility and design stages of projects where there are numerous opportunities to influence decisions but the components of the framework will continue to be applied throughout the construction and occupancy stages.

The SAVE framework was developed and partially tested on the Dundee Waterfront Development project. This $£ 1$ billion, 30 year project will re-integrate the city centre with the River Tay Estuary and involves the transformation of 240 hectares of development land stretching $8 \mathrm{~km}$ along the River Tay. The area is divided into five focussed zones: Riverside; Seabraes; the Central Waterfront; City Quay and Dundee Port. The University of Abertay Dundee developed the SAVE framework over a five year period to support Dundee City Council and the other project partners in the sustainable development of the Central Waterfront zone. The SAVE framework had to be applied to the infrastructure provision phase of the project due to the phasing of the Waterfront Development. This placed a restriction on the research, enabling the full development and testing of the Assessment and Enhancement components, but limiting the full assessment of the potential of the Visualisation component, in particular of its potential for stakeholder engagement in the master planning process. 


\section{APPPLICATION OF THE SAVE CONCEPT}

\subsection{The Assessment Component}

The Indicator Selection Processes

The first activity for the assessment component was to identify a set of indicators that could provide a means of strategic monitoring of the overall sustainability of the development. These are reported annually to the Dundee Waterfront Management Group, the project participants and to other funding bodies. It was, therefore, essential that a clear understanding was developed by the research team of the nature of the information required by these stakeholders and their use of the information in their decision making processes. This ensured the appropriateness of the indicator set as a monitoring tool and also ensured that they could be fully considered by stakeholders in subsequent sustainability enhancement activities.

The team developed an approach to the indicator identification and selection process that consists of three phases, as suggested by a review of relevant literature (e.g. Graymore et al., 2009, Kowalski et al., 2009, Sheppard and Meitner, 2005 and Gilmour et al. 2011). This is shown in Figure 2. 
Phase 1

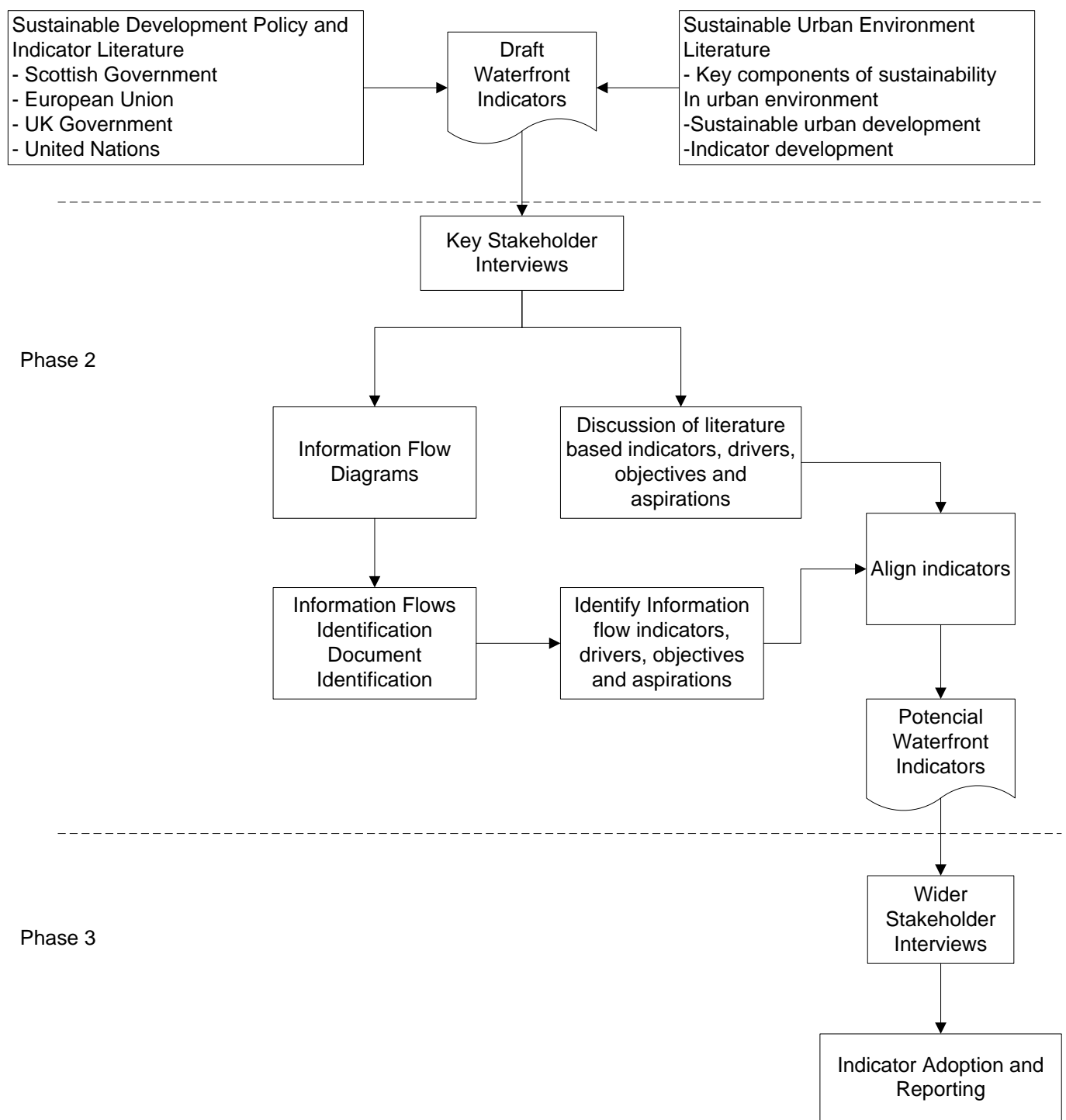

Figure 2. The Indicator Selection Process

Phase 1 involved a pre-selection of Potential Benchmark Indicators from literature.

This included a review of published sustainability monitoring indicator sets and literature on government policies on sustainable development (DETR 1999, UNCSD 2001, DEFRA 2005, UNSD 2005, Scottish Executive, 2006, UN 2007, Scottish Government 2007, DEFRA 2010, Scottish Government 2011). This policy based theme of indicator review was expanded to include (i) more specific indicators for the urban environment, (Urban Task Force, 1999, Egan, 2004, Walton, 2005 McAllister 2005, Boyko, Cooper and Davey 2005, Holden 2008, Davidson et al 2012), (ii) The 
authors' experience of sustainable indicator development (Foxon 2002, Butler, 2003, Ashley 2008) and (iii) relevant sustainable urban development research papers (Maclaren 1996, Innes and Booher, 2000, Deakin 2002, Hemphill, McGreal, Berry 2002, Bartlett and Guthrie 2005, Holden 2006, El-Haram et al 2007, Xing et al 2009). Each indicator on the shortlist was reviewed to identify its appropriateness to the Waterfront project, in relation to its scale, geographical area, units of measurement, and focus and direction. Indicators were then grouped into three categories, Economic, Environmental and Social. A definition for each indicator was then assigned together with draft units.

Phase 2 involved a process of reduction and rationalisation to identify a more manageable number of the most appropriate indicators based on an analysis of the information needs of the stakeholders. The two approaches that were considered for this second phase were the application of decision mapping techniques (e.g. Thomson et al. 2009, Jeffari 2009) and the involvement of selected experts in a multistakeholder forum format (e.g. Sheppard and Meitner, 2005, Elghali et al., 2007 and Buchholz et al., 2009). It was decided that the former approach was appropriate for this study to ensure that the process was inclusive of as wide a range of stakeholders as possible.

Key stakeholders and their information needs were identified using a set of procedures, developed by the authors, including those drawn from IT and knowledge management fields (Butler et al, 2003, Blackwood 2004, Gilmour and Blackwood 2006). The procedures included the production of information flow diagrams (Baldwin et al, 1999, Winch \& Carr 2001, Gilmour 2005) to identify the stakeholders involved in the project and their means of interaction and to categorise the use of the information by the stakeholders. Each of the identified information flows had a 
number of associated documents e.g. data, reports, meeting minutes and each of these were examined to better understand the use of the information. Each document was reviewed and its use was discussed with the stakeholders. In this way key decision points where information was used to support a decision were identified and the nature of the information in making these decisions was established.

Proposed indicators from the literature review were also evaluated in the interviews with these key stakeholders to ensure that they are relevant, analytically sound and measurable. Olsen (2004) identify that well-chosen indicators should focus on materiality and accessibility. Materiality concerns the information stakeholder want and accessibility refers to ability of stakeholders to acquire and understand the information contained in indicators. Winston and Eastaway (2008) state that indicators must be integrating across economic social and environmental dimensions, forward looking to target or goals, distributional in relation to inter and intra generational equity and developed with input from multiple stakeholders. $\underline{\text { Phase } 3}$ involved wider stakeholder interviews. An interview was undertaken with a member of the Sustainable Development Indicator Development Team at the Scottish Government. The interview concentrated on the current and future development of the Scottish Government indicators and future EU and UK indicator reporting. The source and concept of the indicators was discussed and the way in which the indicators related to Scottish Government policy was reviewed. No additional indicators or changes to Scottish Government indicators were foreseen for 10 years. Sources of data for Waterfront indicators were reviewed and potential national data source were identified. Overall the indicators were seen as appropriate for monitoring the sustainable development of Dundee Waterfront. 
Wider Stakeholder interviews were also undertaken with Dundee City Council, Scottish Enterprise and Dundee Partnership stakeholders. The indicators were reviewed through a further set of over 20 indicator meetings with stakeholders (often more than 1 meeting) where they were tested against the four tests of an indicator, namely Comprehensiveness, Tractability, Transparency and Practicability. Particular attention was paid to scope and scale, data availability and methods of data collection with a focus on the establishment of a long term indicator collection mechanism. The full list of stakeholders involved in the selection process is shown in Table 1 together with a summary of their areas of interest. 
Dundee Partnership

Stakeholder

City Engineer, Dundee City

Council.

Waterfront Team Leader,

Dundee City Council.

Partnership Coordinator,

Scottish Enterprise.

Business Infrastructure

Manager, Scottish Enterprise.

Team Leader Policy and

Funding, Corporate Service,

Dundee City Council.

Head of Sustainable

Development and

Environment, Corporate

Planning, Dundee City

Council.

Waterfront Coordinator,

Dundee City Council.

Greenspace Development,
Nature of Feedback on indicators

Governance of Indicators

Infrastructure delivery, management systems, reporting structures

Governance of Indicators, scope and scale

Economic, social indicators, scope and scale, data availability and methods of data collection, Dundee Waterfront Performance Management Framework, Marketing Group

Economic, scope and scale, data availability and methods of data collection, Single Outcome Agreements, Environment indicators, scope and scale, data availability and methods of data collection

Governance of Indicators, scope and scale, Dundee Waterfront Performance Management Framework Environment and biodiversity indicators, scope and 
Dundee City Council.

Monitoring Group Member, Scottish Enterprise.

Infrastructure Group Chair,

Scottish Enterprise.

Senior Community Planning

Officer, Corporate Planning,

Dundee City Council.

Waterfront Team Senior

Engineer, Dundee City

Council.

Team Leader, City

Development, Dundee City

Council

Planning Officer, Information

and Research, Dundee City

Council. scale, data availability and methods of data

collection

Monitoring Group indicators, Dundee Waterfront

Performance Management Framework, Economic

indicators, scope and scale, data availability and

methods of data collection

Infrastructure delivery, Monitoring, Governance

Social indicators, Single Outcome agreements, scope and scale, data availability and methods of data collection

Infrastructure delivery and monitoring KPI

Infrastructure delivery and monitoring KPI

Local Outcome Indicators, scope and scale, data availability and methods of automated data collection

Table 1. Stakeholder Engagement in the Indicator Selection Process

The Potential Benchmark Indicators were further screened for their relevance and practicality in terms of data availability. The Scottish Government has since 2008 required Scottish Local Authorities to develop Single Outcome Agreements (SOA) which are a step change in how local authorities are externally scrutinised. Dundee 
City Council therefore has to effectively demonstrate how they have contributed to national outcomes through identifying local outcomes and relevant indicators. The Benchmarking Indicators for DCW for 2008 were reviewed in response to the SOA national outcomes indicators to identify synergies. National outcomes map well onto the three pillars of sustainability and the DWC indicators therefore can provide information on a large number of SOA indicators either directly (i.e. using the same units) or indirectly. The alignment of the SOA and DCW indicators gives additional confidence in the availability of data and on the long term applicability of the monitoring tool. The Indicators values are either directly included in the report, e.g. the Noise Indicator or some transformation or modelling is required as in the case of the Economic Output Indicator.

The indicator selection process provided an understanding of how and where decisions are made in the Waterfront project and this enabled the selection of the most relevant 18 of the previously identified Potential Benchmark Indicators. These are included in a Baseline Sustainability Indicator Report. The Baseline Sustainability Indicators are shown in Table 2, 3 and 4. 


\begin{tabular}{|c|c|c|c|c|}
\hline Benchmark & Definition of & Units & Baseline & Desired \\
\hline \multirow[t]{2}{*}{ indicators } & indicator & & Data & direction/ \\
\hline & & & & Target \\
\hline Demographics & Population & Population & 142,170 & UP \\
\hline (City Wide) & retention & number & & \\
\hline Retention of & Graduate & Graduate & $33 \%$ & Up \\
\hline skills base (City & retention rate & population & & \\
\hline \multicolumn{5}{|l|}{ Wide) } \\
\hline Knowledge & Knowledge & Percentage of & $28.8 \%$ & Up \\
\hline based & economy sector & jobs in & & \\
\hline employment & jobs & knowledge & & \\
\hline (City Wide) & & industries & & \\
\hline Employment & Employment rates & $\%$ of resident & $72.2 \%$ & Up \\
\hline \multirow[t]{2}{*}{ (City Wide) } & & working age & & \\
\hline & & population & & \\
\hline Capacity to & Total inward & $£$ Inward & 0 & Up \\
\hline stimulate & investment to & investment & & \\
\hline investment & waterfront & & & \\
\hline \multicolumn{5}{|l|}{ (Direct) } \\
\hline Tourism & Tourists visiting & Number & 72,061 & Up \\
\hline numbers & city centre & & & \\
\hline (City Wide) & locations & & & \\
\hline
\end{tabular}




\begin{tabular}{lllll}
\hline Tourism & Level of tourism & Expenditure & $£ 130.79 \mathrm{M}$ & Up \\
(City Wide) & expenditure & & & \\
& Dundee & & & \\
& Increased & \% Increase & 0 & Up \\
Regeneration & property value & & \\
(Direct) & Number of jobs & Number & 0 & UP \\
Job creation & created & & & Up \\
(Direct) & Economic output & GDP per capita & $£ 17,335$ & \\
Economic output & & & & \\
(City Wide $)$ & & & & \\
\hline
\end{tabular}

Table 2. Benchmark Indicators - Economic 


\begin{tabular}{|c|c|c|c|c|}
\hline Benchmark & Definition of & Units & Baseline & Desired \\
\hline \multirow[t]{2}{*}{ indicators } & indicator & & Data & direction/ \\
\hline & & & & Target \\
\hline Green & Local & Green space & Not yet & Excellent \\
\hline space/public & environmental & quality standard & available & \\
\hline space & quality & & & \\
\hline \multicolumn{5}{|l|}{ (Direct) } \\
\hline Waste & Construction waste & $\%$ of projects & $100 \%$ & To match \\
\hline \multirow[t]{4}{*}{ (Direct) } & recycling & where waste re & & national \\
\hline & & used/ recycled & & best \\
\hline & & in line with best & & practice \\
\hline & & practice & & \\
\hline Air & Air emissions & Emissions of , & 36.6 & Down \\
\hline \multirow[t]{4}{*}{ (Direct) } & continually & $\mathrm{NO}_{2}$ average & & \\
\hline & monitored at & $\mu \mathrm{g} / \mathrm{m}^{3}$ & & \\
\hline & Union Street and & & & \\
\hline & Seagate & & & \\
\hline Water & Per capita water & 1/head/day P.E. & Not yet & To match \\
\hline \multirow[t]{3}{*}{ (Direct) } & use & & available & national \\
\hline & & & & best \\
\hline & & & & practice \\
\hline Noise & Noise level impact & Number of & 0 & Down \\
\hline (Direct) & & complaints & & \\
\hline
\end{tabular}




\section{related to DCW}

construction

\begin{tabular}{|c|c|c|c|c|}
\hline Energy & Energy & Energy use $/ \mathrm{CO}_{2}$ & Not yet & To match \\
\hline \multirow[t]{2}{*}{ (Direct) } & consumption & per M2 of & available & national \\
\hline & & property & & $\begin{array}{l}\text { best } \\
\text { practice }\end{array}$ \\
\hline Travel & Journeys to work & $\%$ Journeys & $15 \%$ & Up \\
\hline (City Wide) & $\begin{array}{l}\text { and school made } \\
\text { by pubic or active }\end{array}$ & & & \\
\hline & transport & & & \\
\hline
\end{tabular}

Table 3. Benchmark Indicators - Environmental 


\begin{tabular}{|c|c|c|c|c|}
\hline Benchmark & Definition of & Units & Baseline & Desired \\
\hline indicators & indicator & & Data & direction/Target \\
\hline Housing & Residential & $\%$ of & $21 \%$ & $21 \%$ \\
\hline provision & development & residential & & \\
\hline (Direct) & & development & & \\
\hline Health \& Well & Positive and & $\%$ of school & $85 \%$ & Increase \\
\hline being & sustained & leavers in & & \\
\hline \multirow[t]{4}{*}{ (City Wide) } & destinations & positive and & & \\
\hline & (education, & sustained & & \\
\hline & employment or & destinations & & \\
\hline & training) & & & \\
\hline Community & Neighbourhood & $\%$ Resident & Quality 83\% & Up \\
\hline \multirow{7}{*}{ (City Wide) } & satisfaction & satisfaction & Access 93\% & \\
\hline & & with the & & \\
\hline & & quality of and & & \\
\hline & & access to local & & \\
\hline & & services, & & \\
\hline & & facilities and & & \\
\hline & & environment & & \\
\hline Social Inclusion & Accessibility of & Uptake of & Survey in & \\
\hline \multirow[t]{2}{*}{ (City Wide) } & cultural and & cultural & October & \\
\hline & learning & opportunities & 2013 & \\
\hline
\end{tabular}




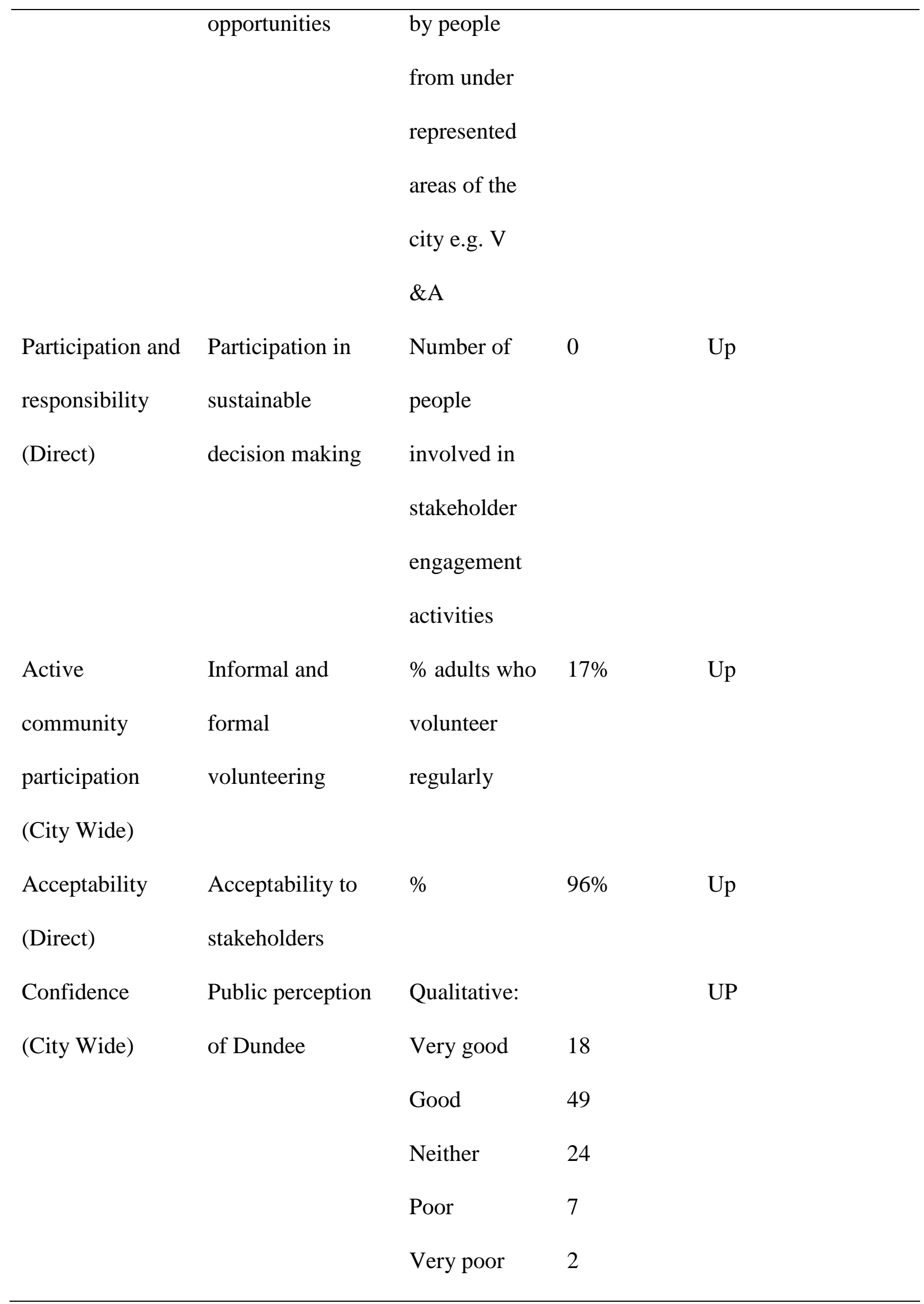




\begin{tabular}{|c|c|c|c|c|}
\hline Amenity value & Public perception & Qualitative & Not yet & Excellent \\
\hline \multirow[t]{2}{*}{ (City Wide) } & of amenity of & & available & \\
\hline & Waterfront area & & & \\
\hline
\end{tabular}

\section{Table 4. Benchmark Indicators - Social}

Data Collection, Manipulation and Reporting of Trends.

The interpretation and reporting of indicators is essential as it bridges the gap between measurement and understanding (Brown, 2009). Progress towards sustainability is monitored in an Annual Sustainability Monitoring Report, which is published on the Waterfront Development and Dundee City Council websites and presented to the Waterfront Partnership Monitoring group meeting. . The Sustainability Monitoring report presents stakeholders with an update on any changes in the values of the 18 Benchmark Indicators together with a commentary on the trends in their direction.

\subsection{The Enhancement Component}

The Enhancement component of SAVE identifies opportunities to positively influence the sustainability of the development and to devise and implement appropriate activities and actions. This requires an understanding of the ways in which decisions are made throughout the project.

A number of authors have effectively used decision mapping or knowledge mapping to document and understand an organisations' knowledge management and decision making processes (Snowden 2000, Wexler 2001, Vestal 2005, Driessen 2007, Yasin and Egbu 2010). A review of literature in this field enabled the development of a knowledge elicitation and mapping methodology to identify opportunities for enhancement activities This consisted of three stages: 
1. Knowledge Elicitation and process mapping to identify and classify knowledge and identifying key decision points.

2. The creation, through stakeholder workshops, of a verified knowledge map of sustainable decision making on the Waterfront Development project.

3. Workshops with key process owners to link existing management systems to key decision points and hence to identify opportunities to ensure the full integration of sustainability issues into the Waterfront project decision making process.

An example of the outcome of Stages 1 and 2 are shown in Figure 3. A three-level process mapping approach was used. Level 1 process diagrams present an overview of all stages involved in the Waterfront Development and Level 2 and 3 diagrams capture increasing levels of detail of the processes, workflows and hence the key decision points. In this example the knowledge objects; Clients Requirements, Experience, Training and Engineering Judgement are used alongside Model Outputs and other documented knowledge objects in the decision process. This mapping approach also allows process and Knowledge Disclosure Points, such as decisions, judgements, problem resolution (Snowden, 2000), to be captured. Knowledge Objects used in the process are then collated for categorisation and analysis. 


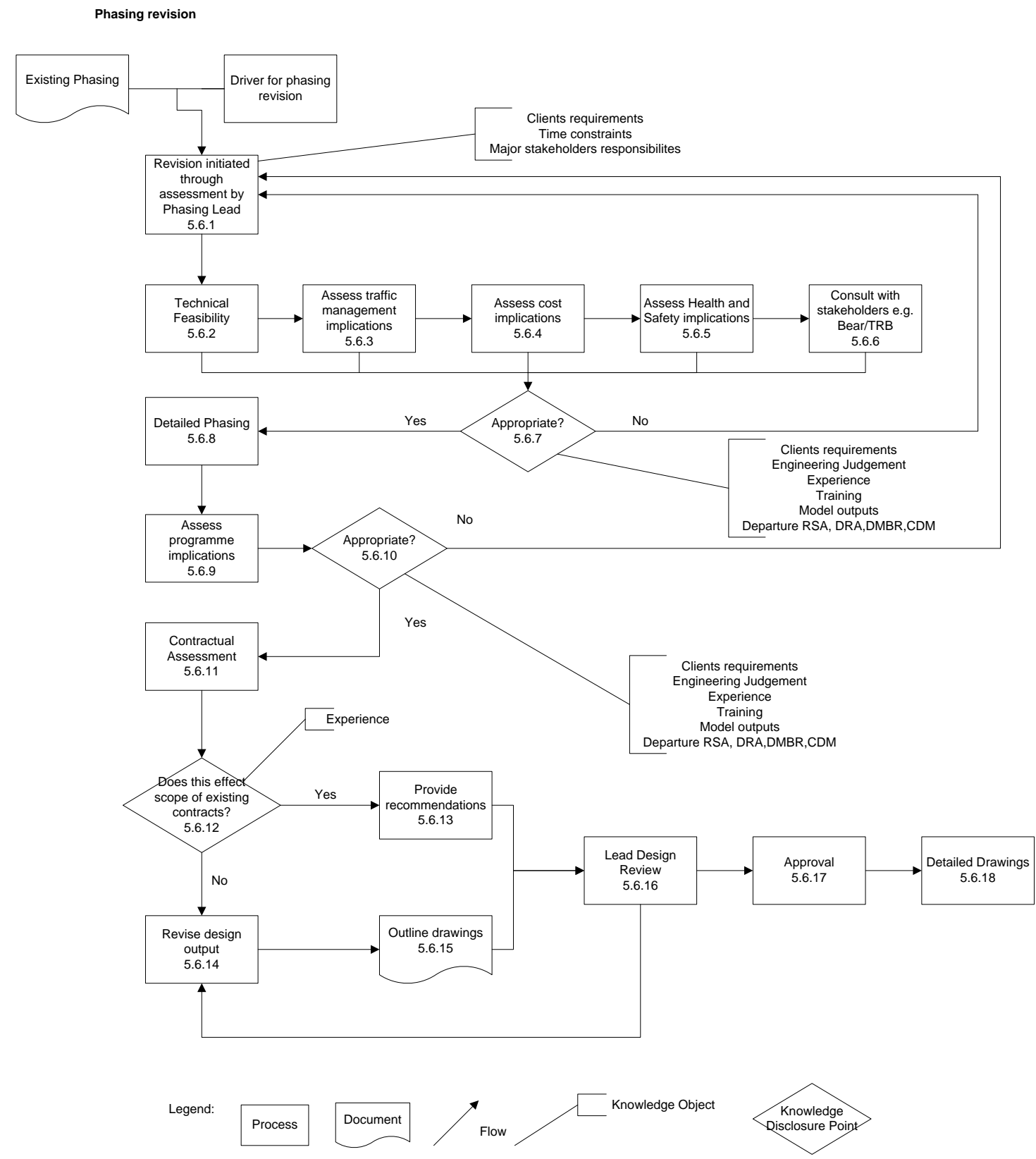

Figure 3. Example of a Knowledge Map - Level 3 Phasing Revision

Activities.

Workshops were then held with the Waterfront Project team to review the Knowledge maps and hence to identify opportunities for sustainability enhancement interventions within the Enhancement component of SAVE. In this case study the knowledge elicitation and mapping process for the Enhancement Component was undertaken 
following the identification of the Sustainability Indicators for the Sustainability Assessment component and built upon the interviews carried out at the Assessment stage, However it is recommended that the knowledge mapping for the assessments and enhancement activities should be carried out in parallel in future projects. This would ensure a more direct link between monitoring indicators and enhancement activities, which will maximise the potential for the interventions to positively influence the direction of the indicators.

The enhancement activities focussed on the master planning and infrastructure provision stage of the Waterfront Development Project as dictated by the timing of the research study in relation to the overall Waterfront Development programme. Opportunities were identified from the knowledge maps and workshops to enhance sustainability at a number of sub-stages from specifying the vision in the conceptual master plan to operation and maintenance of infrastructure when complete as shown in figure 4.

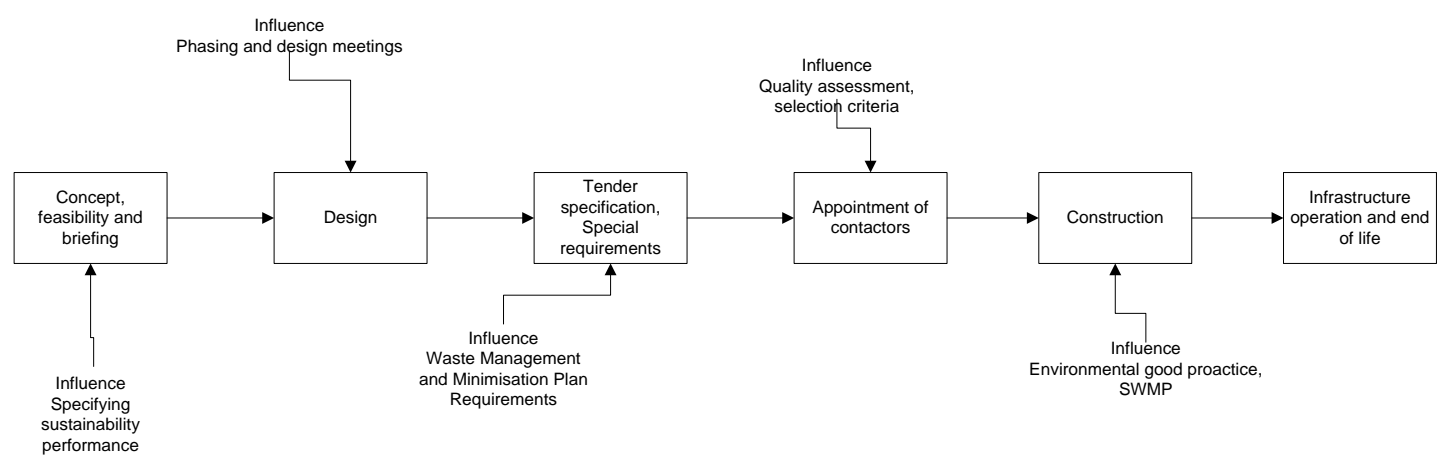

Figure 4. Example of sustainability interventions in the project life

The process of identifying enhancement activities or interventions using Knowledge Maps is illustrated with reference to the Knowledge Map shown in Figure 3. The Construction Design Management (CDM) documented knowledge object presented 
an opportunity to positively influence sustainability. This was achieved by the development and imbedding of a 'Sustainable Development Issues Register' into the CDM process to influence phasing and design of the Dundee Waterfront infrastructure provision. This involved identifying sustainable development issues arising during the design and phasing meetings with design consultants and the Dundee City Council project team. During these meeting the issues driving the design and phasing in relation to the Sustainability Monitoring Indicators were identified. These were then either raised and dealt with during the meeting if appropriate, or identified in the Sustainable Issues Register which would subsequently be included in design briefs for future considerations through the Councils project management systems.

A number of project sustainability issues were identified by the Sustainability Issues Register and followed up during the design and phasing stages. For example the registered helped to ensure that phasing was driven by a prime driver of minimising disruption to public. Examples of this were a decision to bringing forward demolition of the Tay Bridge access ramps to facilitate two lanes at all times to the Tay Road Bridge, which provides commuter access to the city centre to reduce impact to the travelling public. Other sustainability enhancement interventions that were identified from the Level 3 Knowledge Maps included highway phasing and design decisions that ensured that traffic lights and street lighting will be reused on the permanent road layout following their use on temporary road layouts and that road material from temporary routes should also be reused on the permanent layout. 
Other project sustainability issues identified from the Knowledge Maps were the impact of methods of work on local residents and business. These issues were a key driver to the approaches developed for demolition, construction and processing of material on site. As a result, a consultation on the impact of local residents and business has been undertaken between DCW Planning coordinator, Engineering team, Environmental Health and Trading Standards (EHTS) and local residents and business. This has resulted in adapting methods of work such as a 40 decibel working limit during the night and the restriction or ruling out of long term night time working and peak time lane closures.

\subsection{The Visualisation component}

In addition to annual sustainability reporting and communication in a traditional written format, the presentation of sustainability data can be customised to the needs of various stakeholders using the Visualisation component of the SAVE framework. Whilst some stakeholders may be able to draw meaning from the indicator set, other stakeholders will prefer some form of aggregation of the indicators to provide a quantitative assessment of the overall sustainability of the development using, for example, simple weighted aggregate functions or decision support software packages such as ELECTRE (Salminen, Hokkanen, and Lahdelma, 1998). As previously discussed, sustainability assessment and enhancement takes place within a sociotechnical system and the complexity of such a system is difficult to comprehend. Information visualization has been proposed as a possible approach to analysing and interpreting such data (Kapelan et al. 2005; Al-Kodmany 2002). The stakeholder can be presented with a $3 \mathrm{D}$ visualisation of the development that encapsulates the results of the models and thus the relative sustainability of the development. A visualisation 
tool, S-City VT (Isaacs et al., 2011), has been developed that employs a number of different methods to display the sustainability results to the stakeholders. These methods show data in varying levels of complexity, depending on the stakeholder's needs, empowering all stakeholders by illustrating possible trade-offs between indicator values and sustainability. Further the tool will model and visualise, using an animated simulation through time, the results of decisions made at different stages which affect the indicator values during the development allowing comparisons to be made. The visualisation platform consists of three nodes as shown in Figure 5, two of which are concerned with data manipulation.

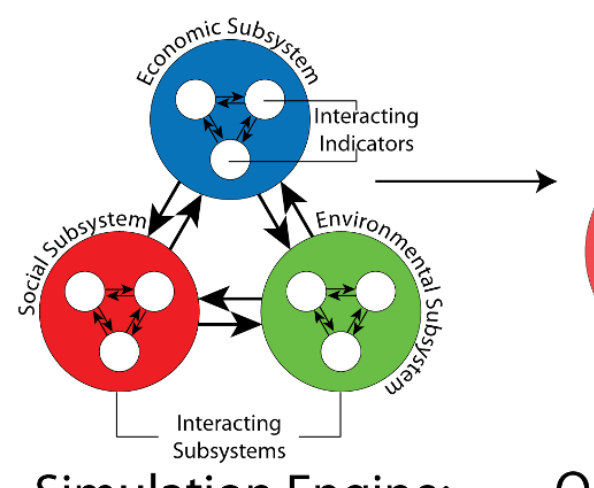

Simulation Engine:

Environmental, Social and Economic indicator Models

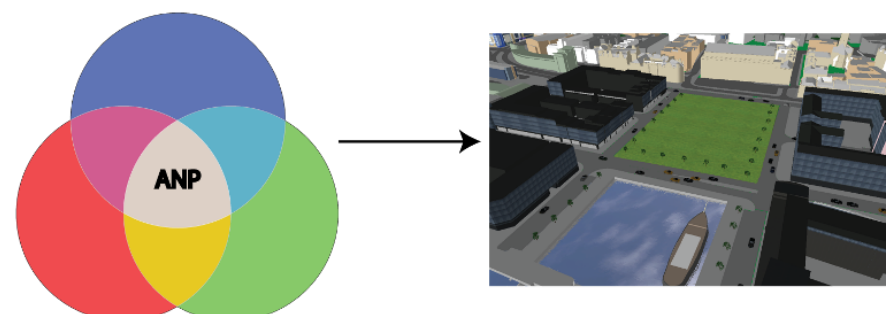

Opinion Analysis:

Analytic Network Process, multi-criteria analysis of user opinion and experience
3D Visualisation: Virtual environment \& visualisation techniques

Figure 5. Data modelling and transformation stages 


\section{Simulation}

Six of the 18 criteria were selected from the Dundee Waterfront project monitoring set for inclusion in the prototype Visualisation component of SAVE. The indicator modelling involved sub models that define how each of the indicators varies over space and time. The specific six indicators chosen to be modelled provide a spread across the sustainability domains (economy, society and environment) and were identified as having readily available data at the beginning of the case study. The prototype indicator models are described briefly below.

(i) The energy efficiency model is based on the Nation Calculation Method (NCM) which is the industry standard allowing energy efficiency of buildings to be determined (BRE, 2009). (ii) The noise model calculates the levels of traffic noise at each building and is mapped to a nuisance factor based on projected traffic volumes and the CRTN (1988) function (iii) The economic model utilises a discounted cash flow calculation to determine the worth of a building's current cash flow for a specific point in time. (iv) Public acceptability represents the acceptance of possible building uses and forms within the development. An on line survey was undertaken the result of which ranked building use as ; Leisure (highest ranked), Retail \& Residential (equal ranked) and Commercial (Lowest Ranked). This information was used to create sustainability index (0-100) for the acceptability of each building. (v) The Housing provision model calculates the percentage of the building designated as residential space this provides a sustainability index of $0-100$ which will be comparable with the other models. (vi) The Employment model using existing information regarding different building uses (e.g. commercial, leisure etc) and building sizes to provide the likely number of jobs a specific building might create or sustain. 
Option analysis

One of the problems with traditional sustainability assessment is involving the often conflicting views and experiences of a wide range of stakeholders. Many of the traditional methods of aggregating indicator values, such as Multi Attribute Utility Theory (MAUT), lack transparency leaving the users in a position where they do not fully understand how the resulting weightings have been derived (e.g. Dodgson et al. 2009). The Analytical Network Process (ANP) uses interactive network structures that give a more holistic representation of the overall problem (Saaty, 2006). The prioritised list of elements that are derived from the ANP analysis are used to provide a weighting to the indicators being visualised.

Visualisation

The main purpose of the Visualisation component is to communicate the sustainability Monitoring Indicators, to a wide range of stakeholders thus enhancing their understanding of the underlying sustainability issues. This enables the stakeholders to make an effective contribution to the project development process at the most appropriate intervention points that are identified by the Enhancement component of SAVE. The visualisation component recreates the area undergoing sustainability assessment by combining geospatial data (GIS, Maps and aerial photography) with 3D representations of the urban components (Buildings, roads etc) as shown in Figure 6. This allows the stakeholder to contextualise the area in which the decision is being made, this is likely to improve engagement (Isaacs et al., 2011) and bring a greater level of involvement from all participants in the planning process. 


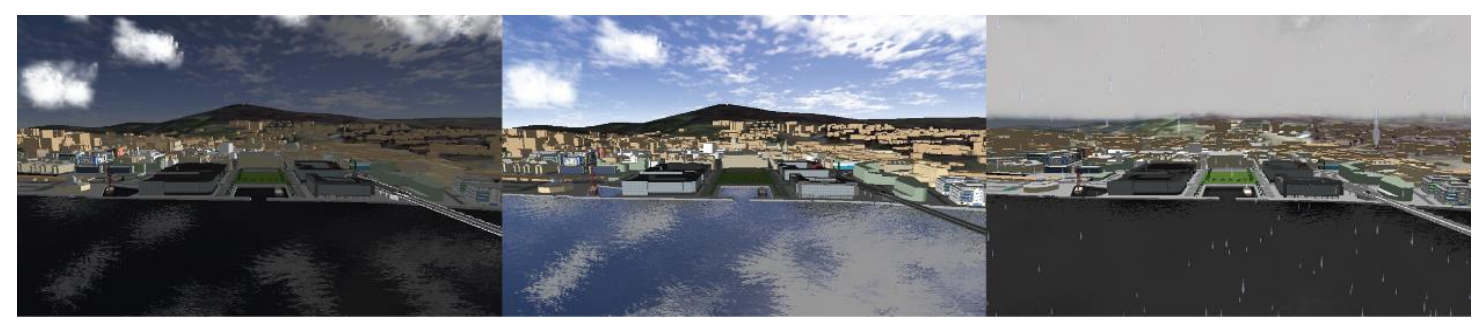

Figure 6. Representation of proposed development within the city-wide context with different lighting and weather conditions.

This coupling of visualisation and simulation is possible as optimised processing for rendering is used which leverages the power of the Graphics Processing Unit (GPU) for rendering whilst the computation is processed by the Central Processing Unit (CPU). This seamless coupling of computation and rendering was made possible by the development of customised software infrastructure. The software permits scenario comparison, where the user can compare two scenarios side by side through time i.e. throughout the life cycle of the development. Changes to the scenario can be made (e.g. change building location, appearance ) and the impact of these are immediately realised via the underlying sub-models of the Sustainability Indicator values and displayed to the user via a number of novel visualisation techniques. Several visualisation techniques have been used to display the results of the underlying sub models as shown in Figure 8, which allows the user to not only compare the external appearance of the different scenarios (Figure 7) but also the relative sustainability of each scenario. Figure 7 shows two buildings that are being compared. Figure 9 shows the blending visualisation technique where the ANP method is used to produce an aggregated indicator of sustainability. Figure 9 shows a weaving technique (HaghShenas 2007) where of each of the 6 indicators are mapped to a colour which is 
weaved across each building. The radar diagrams on the extreme left and right of

Figures $8 \& 9$ show the individual indicator values and their combinations in terms of, social, economic and environmental aspects of sustainable development.

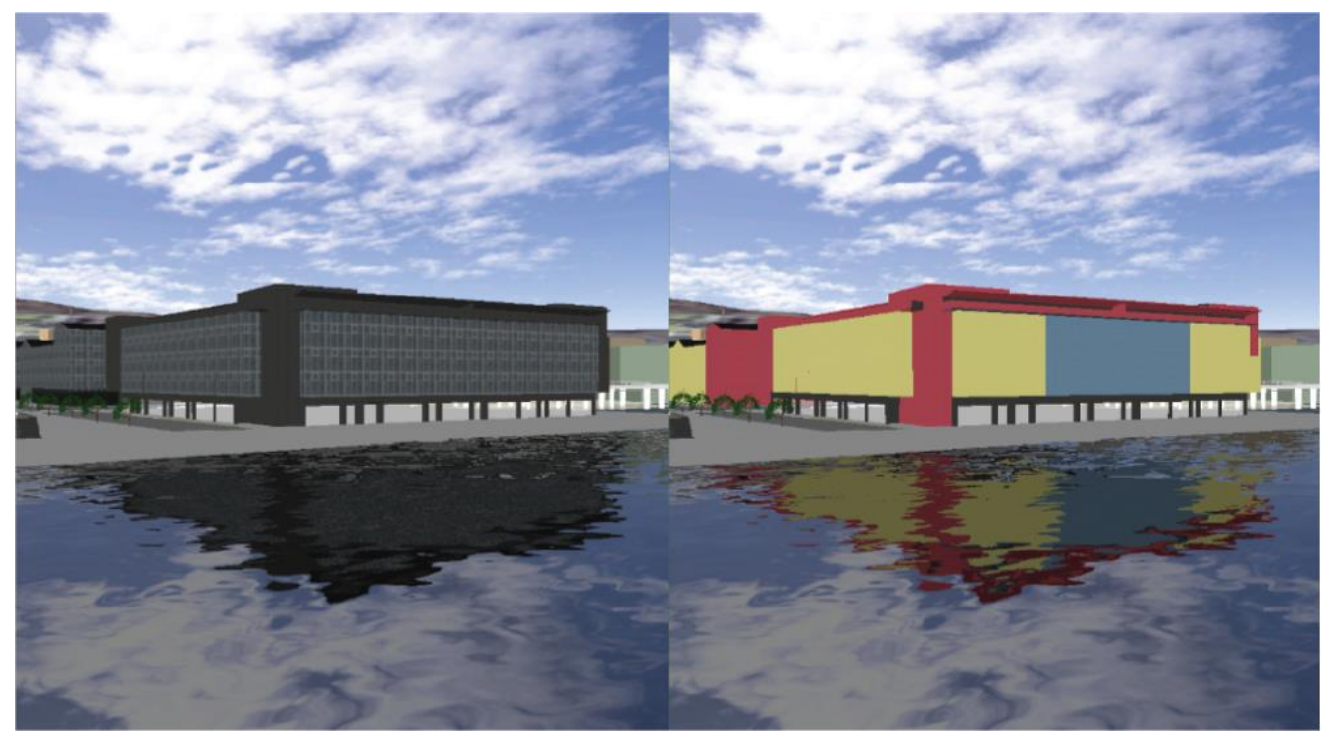

Figure 7. Visual impact assessment using split screen approach.

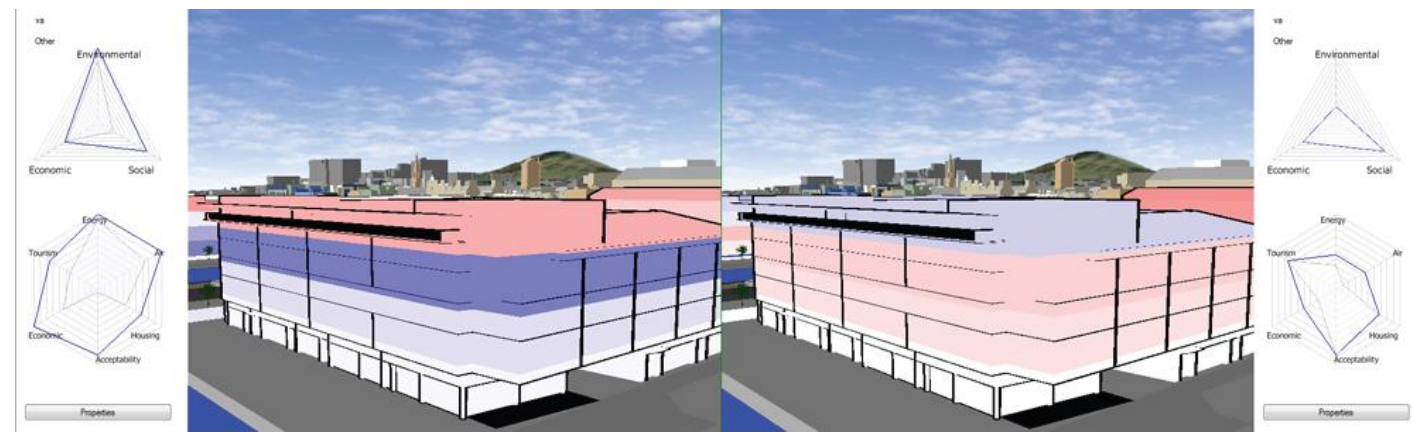

Figure 8. Sustainability assessment - the blend technique.

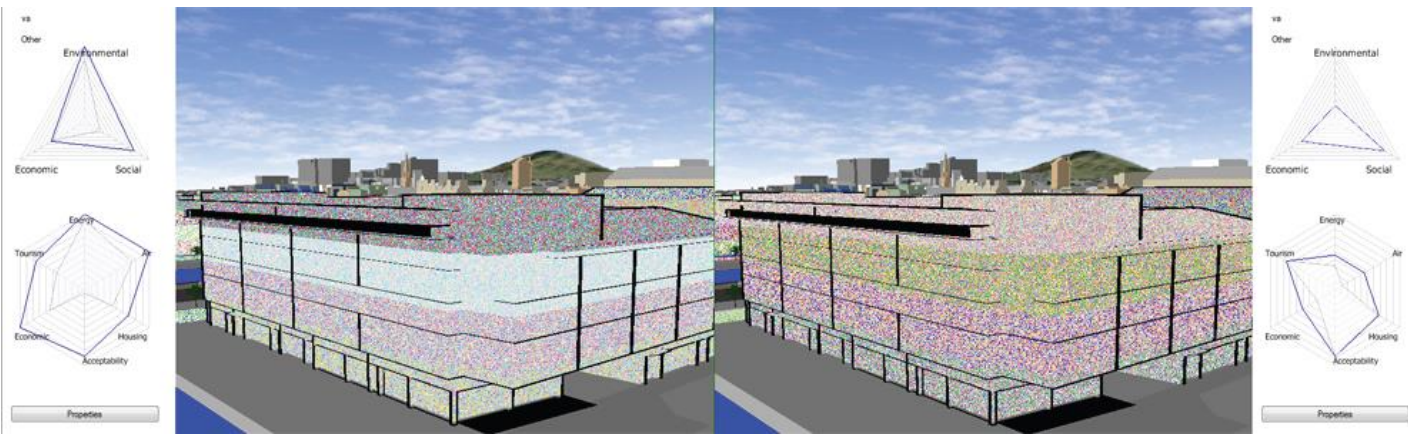




\section{Figure 9. Sustainability assessment - the weave technique.}

Ideally, the Visualisation component of SAVE should be applied as early as possible in an Urban Development project and recent work by the researchers is focussed on its application to public engagement in the master planning stage on other Development Projects. However, the Waterfront Development was at the infrastructure provision stage and master planning had been completed. The visualisation platform was tested by presenting the approved master plan to focus groups and at public exhibitions to assess participant's perceptions of the value of the component and its capacity to convey relevant information on sustainable development. The five focus groups comprised: (1) civil engineers from a city engineering department and the city's Public Art Officer, (2) local authority planning and transport, roads and economic development experts from a largely rural county with urban centres, $(3 \& 4)$ local authority planning and transportation, economic and regional development staff from a more urbanised county and (5) an inner city Community Group. The focus groups confirmed that the inclusion of background buildings and surrounding landscape together with noticeable city landmarks enables the visualisation to provide a geographical context that has been lacking in other sustainability assessment tools. Stakeholders were also able to frequently determine the best scenario, in terms of sustainability, given two options using the different visualisation techniques. Table 5 presents the results of a test with one of the stakeholder groups on their understanding of the sustainability assessment that was presented by the weave technique shown in Figure 9. Eleven tests of weave technique were undertaken and participants correctly identified which scenario was most sustainable in 8 of the 11 cases where the overall relative sustainability differed by 0 , $6,10,20,40,60,80$ and $100 \%$. The more sustainable scenarios were not correctly 
identified where the overall relative sustainability differed by 2,4 and $8 \%$. The indicator that was the origin of the difference was correctly identified 7 of the 10 possible cases. The performance of this group was mid-range when compared to the other groups. The two highest performing groups correctly identified the more sustainable scenario and the origin indicator in all cases whilst the lowest performing group identified $45 \%$ of scenarios correctly and $50 \%$ of origin indicators. The fifth group's results were similar to the example in Table 5.

\begin{tabular}{cccccl}
\hline Test & \multicolumn{2}{c}{ Participant Selection } & \multicolumn{4}{c}{ Most sustainable scenario } \\
Weave & Scenario & Indicator & Scenario & \%Difference & Indicator \\
1 & 1 & Tourism & 2 & 100 & Tourism \\
2 & 0 & & 2 & 80 & Economics \\
3 & 2 & Tourism & 2 & 20 & Tourism \\
4 & 0 & & 2 & 40 & Not Applicable \\
5 & 1 & Acceptability & 0 & 0 & Acceptability \\
6 & 1 & Acceptability & 2 & 4 & Acceptability \\
7 & 0 & & 2 & 8 & Tourism \\
8 & 0 & & 1 & 6 & Tourism \\
9 & 1 & Economic & 1 & 60 & Economic \\
10 & 1 & Economic & 2 & 2 & Economic \\
11 & 1 & Housing & 1 & 10 & Housing \\
\hline
\end{tabular}

Table 5. Example of stakeholder tests of weave technique 
The observations and transcriptions taken during the focus groups also showed that by far the highest proportion of time in each testing session was spent discussing the decisions being made. It was evident that those groups where most discussion occurred performed best in the scenario choice tasks using the visualisation techniques and also that these groups, through their discussions, were able to guide each other to the correct choice. The ability of the tool to engage wider stakeholders was further demonstrated through testing at a number of public events, such as the Dundee City Science Festival. There was significant interest in the visualisation and participants frequently commented that they had never before seen the waterfront plans presented in such an engaging way. The testing has suggested that the visualisation platform can provide an opportunity for public engagement, particularly in the early project design and development stages through the presentation and discussion of data related to the Sustainability Monitoring Indicators. This will also enable the views of wider communities to be more fully considered within the subsequent sustainability enhancement activities.

\section{DISCUSSIONS AND CONCLUSION}

The incorporation of sustainability assessment and enhancement within major urban development projects presents a number of challenges. Firstly, the development process is complex and takes place over long timescales. This requires the consideration of a wide range of environmental, economic and social issues, which involves input from a wide range of stakeholders. Furthermore, these stakeholders have differing information needs and provide input at various stages to the process. Secondly, the degree of rationality of current decision making processes must be enhanced. Traditional planning and design approaches have been viewed as a passive 
exercise with planners and designers acting as expert and rational decision makers, using mainly quantitative approaches to data collection and analysis. However, this may lead to decisions that are satisfactory rather than optimal having been judged only against a limit set of criteria. Ensuring that sufficient emphasis is given to all aspects of sustainability requires the elicitation and communication of information in a wide range of forms, from and to, a wide range of stakeholders who have differing information needs. Therefore, sustainability assessment and enhancement requires the identification and provision of meaningful information on the various aspects of sustainability to the right stakeholders, in the right form and at the right stage of the process.

Thirdly, there is a need to "operationalise" the principles of sustainable development in decision making process throughout the project life cycle. Monitoring alone cannot ensure that the most favourable final outcome is achieved. Opportunities must be identified throughout the process to allow a wide range of stakeholders to inform decisions and then engage in and influence the project implementation.

In response to these challenges, a Sustainability Assessment, Visualisation and Enhancement (SAVE) framework has been developed by the University of Abertay Dundee and piloted on the Dundee Central Waterfront Development project. Its three interlinked components address the challenges above and include: (i) a process for the selection of appropriate sustainability indicators to allow the assessment and monitoring of sustainability throughout a projects life-cycle; (iii) a process of identification of key decision points, the stakeholders involved in the decisions and their information needs and (iii) modelling techniques to provide data for the assessment of indicators and for the prediction of their future trends, integrated within 
a visualisation tool to facilitate the effective communication of this information in an appropriate form to a wide range of stakeholders at the key decision points.

The SAVE framework has been applied to the infrastructure design and construction stages of the Dundee Central Waterfront project, which has allowed partial verification of the SAVE concept. The Assessment component has been fully applied and a robust set of eighteen monitoring indicators have been identified, approved and adopted by the project stakeholders. A Sustainability Baseline Indicators report has been published in 2012 by the Waterfront project steering group and this will be disseminated widely to stakeholders. An annual Sustainability Indicator Monitoring report will be published which provides an update of the indicator values and enable an assessment and reporting of changes and trends in the sustainability throughout the life of the project.

The application of Enhancement component has enabled the verification of the indicator set and has identified key decision points where opportunities exist to influence the direction of the sustainability indicators and hence the overall sustainability of the project. Ideally the Assessment and Enhancement activities would have been undertaken in parallel during the master planning stage to maximise the uptake of the interventions at subsequent stages. However the Waterfront project master planning was completed before the research commenced and the project partners required that the research should initially focus on the Assessment component. There was a resulting lag between the commencement of the work on the Assessment and Enhancement components of approximately 18 months, which reduced the potential for the implementation by the Waterfront team of the enhancement interventions. Nevertheless, many of the interventions have been 
adopted by the infrastructure design and project management team, which suggests that the Enhancement Activities were effective.

Due to project timelines, the visualisation component could not be applied to Waterfront project programme to support Enhancement Stage activities. It was however used to promote the vision of the waterfront to community groups and it was shown that interactive $3 \mathrm{D}$ visualisation was a valuable tool. Tests with a range of stakeholders have demonstrated its general effectiveness in communicating temporal information and stimulating engagement and discussion on the sustainability of building design options for the Waterfront Development.

Overall, the SAVE integrated concept has been developed and partially tested on the Dundee Central Waterfront project. Stakeholder engagement with the concept has been demonstrated as evidenced by the publication of the Baseline Sustainability Assessment report, the commitment to publish annual Sustainability Monitoring reports and by the positive reaction to, and interpretation of, the visualisation of sustainability indicator data by a range of stakeholders. Furthermore, key decision points in the infrastructure provision phase of the Waterfront project have also been successfully identified and sustainability enhancement interventions have been devised and adopted by stakeholders.

Further development and testing of the visualisation tool is planned during the building design stage of the Waterfront Project and initial work has commenced on the application of the SAVE concept earlier in a project development process i.e. to the master planning stage of a major urban development in Fife. This will allow the necessary further testing, particularly on the interaction between the Enhancement and Visualisation components of the SAVE concept. 


\section{REFERENCES}

Al-Kodmany, K,, 2002. Visualization tools and methods in community planning: from freehand sketches to virtual reality. Journal of Planning Literature, 17(2), 189. doi: $10.1177 / 088541202237335$.

Ashley, R., Blackwood, D., Butler, D., Jowitt, P., Davies, J., Smith, H., Gilmour, D. and Oltean-Dumbrava C., 2008. Making Asset Investment Decisions for Wastewater Systems that include Sustainability. ASCE Journal of Environmental Engineering, 134, No. 3, March, 200-210

Asimow, M., 1962. Introduction to design, Englewood Cliffs:Prentice-Hall.

Baldwin, A.N., Austin, S.A., Hassan, T.M. and Thorpe, A. 1999. Modelling information flow during the conceptual and schematic stages of building design. Construction Management and Economics, 17, pp.155-167.

Bartlett, H.V. and Guthrie, P., 2005. Guides to sustainable built environment development. Proceedings of the Institution of Civil Engineers - Engineering Sustainability 158. (4) pp 185-195.

Beck, M.B., Thomson, M., Ney, S., Gyawali, D., and Jeffrey P., 2011. On Governance for re-engineering city infrastructure. Proceedings of the Institution of Civil Engineers - Engineering Sustainability, 164, (2), 129-142. doi:

10.1680/ensu.2011.164.2.129.

Bell, S., Chivers, A. and Hillier, J., 2011. The Socio-technology of engineering sustainability. Proceedings of the Institution of Civil Engineers - Engineering Sustainability, 164, (3), 177-184. doi: 10.1680/ensu.2011.900014.

Blackwood, D.J., Gilmour, D., Ball, L., Dobson. T.and Taylor, A., 2004. Knowledge retention and transfer in the operation of wastewater treatment plants. Proceedings 
Novatech 2004, 5th International Conference, Lyon, France, June. 673-480. 16091616

Boyko, C.T., Cooper, R. and Davey C., 2005. Sustainability and the urban design process. Proceedings of the Institution of Civil Engineers - Engineering Sustainability 158 (3) pp 119-125.

BRE, 2009. National Calculation Method. Available at: http://www.ncm.bre.co.uk/ [Accessed July 7, 2011]. Highways Agency, 1994. Design Manual for Roads and Bridges. Volume, 11 (August).

Brown, D., 2009. Good Practice Guidelines for Indicator Development and Reporting. oecd.org, (October). http://www.oecd.org/dataoecd/19/60/43586563.pdf.

Buchholz T., Luzadis, V.A. and Volk V., 2009. Sustainability criteria for bioenergy systems: results from an expert survey, J. Clean. Prod. 17 S86-S98.

Butler D., Jowitt P., Ashley R., Blackwood D., Davies J., Oltean-Dumbrava C., McIkenney G., Foxon T., Gilmour D., Smith H., Cavill C., Leach M., Pearson P., Gouda H., Samson W., Hendry S., Moir J., Bouchart F., 2003. SWARD:decision support processes for the UK. Management of Environmental Quality, 14, 4, 444459.

CIRIA (Construction Industry Research and Information Association), 2001. Sustainable Construction- Company Indicators. WS Atkins Consultants. CIRIA, London, Publication C563.

CIRIA (Construction Industry Research and Information Association), 2004.

Sustainable Construction- Implementing Targets and Indicators. Experiences from Ciria's Pioneer's Club. CIRIA, London, Publication C633.

CRTN, 1988. Calculation of Road Traffic Noise. (Department Of Transport, Eds.). London: HMSO. 
Davidson, K. M., Kellett, J., Wilson, 1. and Pullen, S., 2012: Assessing urban sustainability from a social democratic perspective: a thematic approach, Local Environment: The International Journal of Justice and Sustainability, 17:1, 57-73 Deakin, M., Huovila, P., Rao, S., Sunikka, M. and Vreeker, R. 2002. The assessment of sustainable urban development. Building Research \& Information, 30(2), pp.95108. Available at: http://www.tandfonline.com/doi/abs/10.1080/096132102753436477.

DEFRA, 2005. The UK Government Sustainable Development Strategy. Department of Environment, Food and Rural Affairs. The Stationery Office Limited on behalf of the Controller of Her Majesty's Stationery Office 03/05,176844

DEFRA, 2010. Measuring progress Sustainable development indicators Department for Environment, Food and Rural Affairs. Crown copyright 2010 DETR, 1999 A better quality of life: a strategy for sustainable development for the UK. Cm 4345. Department of the Environment, Transport and the Regions. TSO May 1999.

DETR, 1999. Towards an Urban Renaissance, the Final Report of the Urban Task Force. Urban Policy Directorate, Office of the Deputy Prime Minister, Department of the Environment, Transport and the Regions Urban Policy Directorate, Office of the Deputy Prime Minister, 29 July 1999.

Dodgson, J., Spackman, M., Pearman, A. and Phillips, L., 2009. Multi-criteria analysis: a manual. Journal of Multi-Criteria Decision Analysis (Vol. 11). London: Department for Communities and Local Government.

Driessen, S., Huijsen, W-O. and Grootveld, M., 2007, A framework for evaluating knowledge-mapping tools, Journal of Knowledge Management, 11, (2), pp. 109-117. 
Egan J., 2004. The Egan Review: Skills for Sustainable Communities. Office of the Deputy Prime Minister. April 2004. Reference no: 04UPU1892 ISBN 1859461425. Elghali, L., Clift, R., Sinclair, P., Panoutsou C. and Bauen A., 2007. Developing a sustainability framework for the assessment of bioenergy systems, Energy. Policy. 35 (2007) 6075-6083.

El-Haram, M. \& Walton, J., Horner, M., Hardcastle, C., Price A., Bebbington, J. Thomson. C and Atkin-Wright T., 2007. Development of an Integrated Sustainability Assessment Toolkit. M Horner et al., eds. International Conference on Whole Life Urban Sustainability and its Assessment, (November), p.1-14.

Foxon, T.J., McIlkenny, G., Gilmour, D., Oltean-Dumbrava, C., Souter, N., Ashley, R., Butler, D., Pearson, P., Jowitt, P. and Moir, J., 2002. Sustainability Criteria for Decision Support in the UK Water Industry. Journal of Environmental Planning and Management 45 (2), 285-301.

Gilmour, D. J., Blackwood, D. J., Picken K., 2005. Stakeholder involvement in wastewater treatment design. 10th International Conference on Urban Drainage, Copenhagen, August $21-26$ th.

Gilmour, D. J., Blackwood, D. J., 2006. Mapping Stakeholder Interactions and Information Exchanges Interreg IIIB $3^{\text {rd }}$ Urban Water Conference. Paisley, 26- 28 April 2006.

Gilmour, D., Blackwood, D., Banks, L., Wilson, F., 2011. Sustainable development indicators for major infrastructure projects. Proceedings of the ICE Municipal Engineer, 164(ME1), pp.15-24.

Graymore, M. L. M., Wallis, A.M. and Richards, A. J., 2009. An Index of Regional Sustainability: A GISbased multiple criteria analysis decision support system for progressing sustainability, Ecol. Complex. 6 (2009)453-462. 
Guthrie, P.M. \& Bartlett, H. V., 2005. Guides to sustainable built-environment development. Proceedings of the ICE - Engineering Sustainability, 158(4), pp.185195. Available at:

http://www.icevirtuallibrary.com/content/article/10.1680/ensu.2005.158.4.185.

Hagh-Shenas, H., Kim, S., Interrante, V. and Healey, C., 2007. Weaving versus blending: a quantitative assessment of the information carrying capacities of two alternative methods for conveying multivariate data with color. IEEE transactions on visualization and computer graphics, 13(6), 1270-7. doi: 10.1109/TVCG.2007.70623. Hemphill, L., McGreal, S. \& Berry, J., 2002. An aggregated weighting system for evaluating sustainable urban regeneration. Journal of Property Research, 19(4), pp.353-373.

Holden, M., 2006. Urban indicators and the integrative ideals of cities. Cities, 23(3), pp.170-183.

Holden, M., Roseland, M., Ferguson, K. and Perl, A,. 2008. Seeking urban sustainability on the world stage. Habitat International, 32(3), pp.305-317. Hunt, D., Rogers C. and Birmingham U., 2005. Barriers to sustainable infrastructure in urban regeneration. Engineering, (June), 67-81.

Innes, J.E. and Booher, D.E., 2000. Indicators for Sustainable Communities: A Strategy Building on Complexity Theory and Distributed Intelligence. Planning Theory \& Practice, 1(2), pp.173-186. Available at http://www.tandfonline.com/doi/abs/10.1080/14649350020008378. Isaacs, J.P., Falconer, R. E., Gilmour, D. J. and Blackwood, D. J., 2011. Enhancing urban sustainability using 3D visualisation. Proceedings of the Institution of Civil Engineers - Urban Design and Planning. 164(3): pp.163-173. Available from http://dx.doi.org/10.1680/udap.900034 
Improvement Service, 2012. Menu of Local Outcome Indicators. Improving Local Outcome Indicators Project (ILOIP). Improvement Service. December 2012. Jafari, M., Akhavan, P., Bourouni, A. and Amiri, R.H., 2009. A Framework For The Selection Of Knowledge Mapping Techniques. Journal of Knowledge Management. 10(1).

Kapelan, Z., Savic, D.A. and Walters, G.A., 2005. Decision-support tools for sustainable urban development. Proceedings of the Institution of Civil Engineers Engineering Sustainability, 158(3), 135-142. doi: 10.1680/ensu.2005.158.3.135.

Kowalski K., Stagl S., Madlener R. and Omann I., 2009. Sustainable energy futures: Methodological challenges in combining scenarios and participatory multi-criteria analysis, Eur. J. Oper. Res. 197 1063-1074.

Lindblom, C. E., 1959. The science of muddling through. Public Administration Review, 19, pp 72-88.

March, J.G. and Simon, H. A., 1958. Organisations. Wiley: New York

McAllister, M., 2005. Wellbeing Concepts and Challenges. Discussion paper.

Sustainable Development Research Network, December 2005

Maclaren, V.W., 1996. Urban Sustainability Reporting. Journal of the American Planning Association, 62(2), pp.184-202.

Olsen, L., 2004. Briefing : Sustainability reporting : an anchor, not the answer. Society, (June), pp.63-64.

Reed, M.S., Fraser, E.D.G. \& Dougill, A.J., 2006. An adaptive learning process for developing and applying sustainability indicators with local communities. Ecological Economics, 59(4), pp.406-418. 
Saaty, T.L. and Vargas, L.G., 2006. Decision making with the analytic network process: Economic, political, social and technological applications with benefits, opportunities, costs and risks. Springer Verlag.

Saaty, T. L., 2006. The Analytic Network Process. In Melbourne: Idea Group Inc.

Salminen, P., Hokkanen, K. and Lahdelma, R., 1998. Comparing multicriteria method in the context of environmental problems. European Journal of Operational Research, 104(3):485-496.

Scottish Executive, 2006. Choosing our future. Sustainable Development Indicator Set. Measuring Progress on Scotland's Sustainable Development Strategy. July 2006. Scottish Government, 2007. National Performance Framework. The Scottish Government, November 2011.

Scottish Government, 2011. Achieving a Sustainable Future Regeneration Strategy. The Scottish Government, APS Group Scotland DPPAS12130 (11/11)

Sheppard, S. R. J. and Meitner, M., 2005. Using multi-criteria analysis and visualisation for sustainable forest management planning with stakeholder groups, Forest Ecol. Manag. 207 171-187.

Simon, H. A., 1984. The Structure of ill-structured problems. In: Developments in design methodology, Ed Cross N, Wiley, Chichester.

Simon, H. A., 1976. Administrative behaviour, Free Press, New York.

Snowden, D., 2000. Organic Knowledge Management part one, Knowledge Management, April. Volume 3, Issue 7.

Starkl, M. and Brunner, N., 2004. Feasibility versus sustainability in urban water management. Journal of Environmental Management 71(3): 245-260. 
Sustainable Development Commission Scotland, 2007. Sustainable Development in Scotland: A review of progress by the Scottish Government. Sustainable

Development Commission Scotland. 04/09/2007

Thomson, C. and El-Haram, M., 2009. Case study of new medical science service building, University of St Andrews, SUE-MOT project output, Glasgow Caledonian University.

Thomson, C.S., El-Haram M.A. and Emmanuel R. 2011. Managing sustainability assessment within the project lifecycle, Proceedings of Institution of Civil Engineers, Engineering Sustainability, 164:2, pp. 143-157.

United Nations Commission for Sustainable Development (UNCSD), 2001. From theory to practice: indicators for sustainable development. New York.

United Nations Division for Sustainable Development, 2005. Indicators of

Sustainable Development: Proposals for a Way Forward. Expert Group Meeting on Indicators of Sustainable Development. New York, 13-15 December 2005 United Nations, 2007. Indicators of Sustainable Development: Guidelines and Methodologies, Social and Economic Affairs. October 2007. Third Edition. United Nations publication. ISBN 978-92-1-104577-2.

Vestal, W., 2005. Knowledge Mapping: The Essentials for Success, APQC (May 4, 2005).

Walton, J.S., El-Haram, M., Castillo, N.H., Horner, R.M.W., Price, A.D.F and Hardcastle, C., 2005. Integrated assessment of urban sustainability, Proceedings of Institution of Civil Engineers; Engineering Sustainability, 158, Issue, (June 2005), pp. $57-65$.

Water UK, 2000. Towards Environmental Sustainability: UK Water Industry Environmental Sustainability Indicators (London, Water UK). 
Wexler, M.N., 2001. The who, what and why of knowledge mapping. Journal of Knowledge Management, 5(3), pp.249-264. Available at:

http://www.emeraldinsight.com/10.1108/EUM0000000005868.

Winch, G. and Carr, B., 2001. "Process, maps and protocols: Understanding the shape of the construction process", Journal of Construction Management and Economics, Vol.19, pp 519-531

Winston, N. \& Eastaway, M., 2008. Sustainable Housing in the Urban Context: International Sustainable Development Indicator Sets and Housing. Social Indicators Research, 87(2), pp.211-221.

Xing, Y. et al., 2009. A framework model for assessing sustainability impacts of urban development. Accounting Forum, 33, pp.209-224. Yasin, F. and Egbu, C., 2010 Exploitation of knowledge mapping benefits in the facilities performance evaluation process: a conceptual framework. In: Egbu, C. (Ed) Procs 26th Annual ARCOM Conference, 6-8 September 2010, Leeds, UK, Association of Researchers in Construction Management, 799-808. 